\title{
Contribution of Magnetic Resonance Imaging in Non-Tumoral Hypopituitarism in Children
}

\author{
Catherine Garel $^{\mathrm{a}} \quad$ Juliane Léger ${ }^{\mathrm{b}}$ \\ Departments of a Pediatric Imaging and bediatric Endocrinology, Hôpital Robert Debré, \\ Assistance Publique-Hôpitaux de Paris, Paris VII University, Paris, France
}

\section{Key Words}

Pituitary $\cdot$ Magnetic resonance imaging $\cdot$ Growth hormone deficiency, children $\cdot$ Diabetes insipidus

\begin{abstract}
Background: Magnetic resonance imaging (MRI) is of paramount importance for evaluating the hypothalamo-pituitary axis in children. Methods: We summarize the main points of the MRI technique, and describe the normal appearance of the hypothalamo-pituitary axis as a function of age and pubertal status. The most frequent causes of nontumoral hypopituitarism include anterior pituitary deficiency (growth hormone deficiency may be isolated or associated with other anterior pituitary hormone deficiencies, with or without other malformations, and related to a known genetic abnormality in some cases), isolated hypogonadotropic hypogonadism and posterior pituitary deficiency with or without anterior pituitary hormone deficiency (central diabetes insipidus may be observed without tumor development). Results: We describe in detail the appearance of the adenohypophysis, the pituitary stalk and the neurohypophysis, correlations with hormone deficiencies, the abnormalities that may be associated and progression over time for each condition. Conclusion: An accurate description of hypothalamo-pituitary axis abnormalities is necessary for accurate diagnosis and prognosis evaluation, with certain features suggestive of particular diseases and some prognostic data correlated with phenotype.
\end{abstract}

Copyright $\odot 2007$ S. Karger AG, Basel

\section{KARGER}

Fax +4161306 1234 E-Mail karger@karger.ch www.karger.com

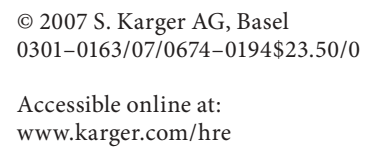

Magnetic resonance imaging (MRI) is the imaging method of choice for evaluating the hypothalamo-pituitary axis in children. It can be used to detect abnormalities and, in some cases, to evaluate the underlying disorder. Evaluation of the hypothalamo-pituitary axis is of paramount importance in some conditions in which the clinical and biological findings are uncertain, as in neonates, for example. The different normal and pathological patterns of the hypothalamo-pituitary axis observed in children will be depicted but this review will not discuss the place of MRI in the diagnostic strategy of growth hormone $(\mathrm{GH})$ deficiency.

\section{Magnetic Resonance Imaging Technique}

MRI of the hypothalamo-pituitary axis includes thin (1- to $1.5-\mathrm{mm}$-thick) T1-weighted slices focusing on the hypothalamo-pituitary area in the coronal and sagittal planes. Contrast medium injection is not essential, and the use of this technique depends on the clinical context and findings in the absence of contrast injection. A contrast agent is systematically injected if accurate imaging of the pituitary stalk is required, as is the case for children presenting hypopituitarism without a spontaneously visible pituitary stalk and for cases of central diabetes insipidus (CDI).

The whole brain must be examined because other abnormalities may be associated with pituitary abnormali- 

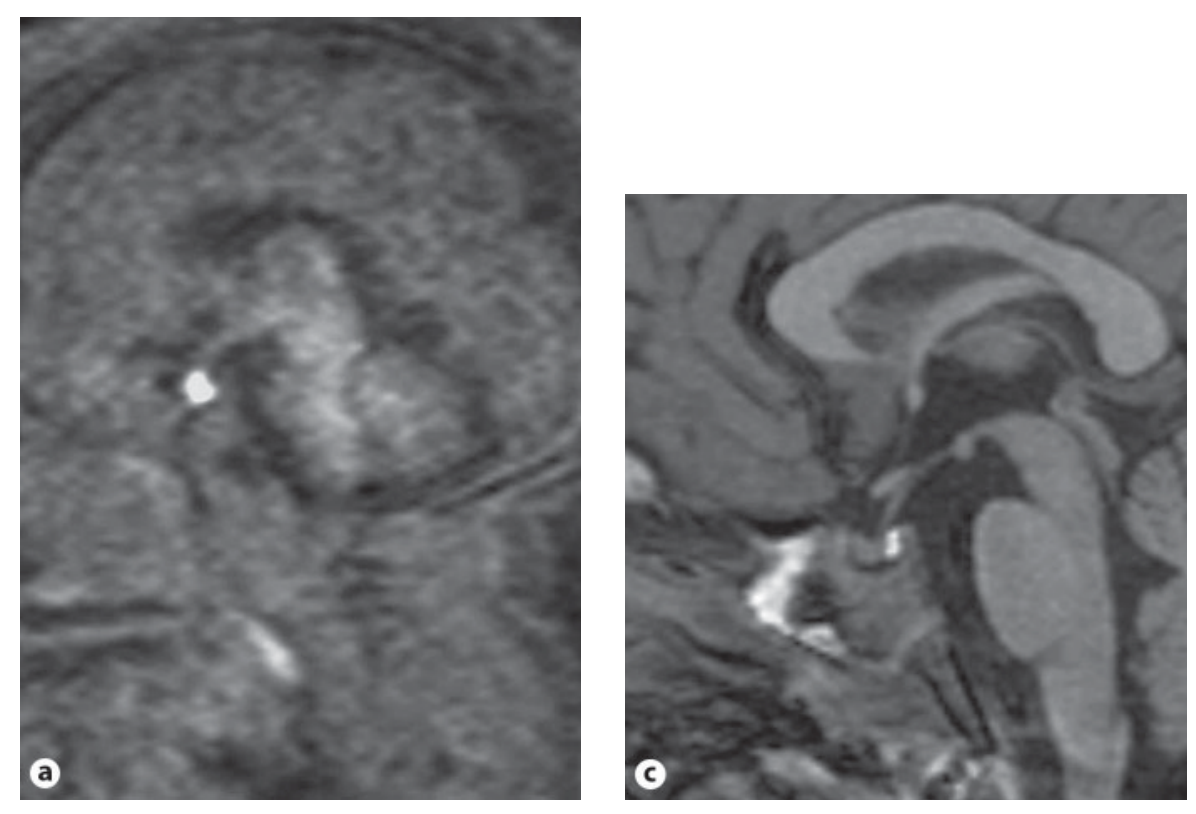

Fig. 1. T1-weighted midline sagittal slice in a fetus (a), a neonate (b), a 7-year-old boy (c) and a 13-year-old girl (d). Note the physiological hyperintensity of the adenohypophysis and the bulbous shape of the pituitary gland in neonates and fetuses. At puberty (d), the pituitary gland is hypertrophied.
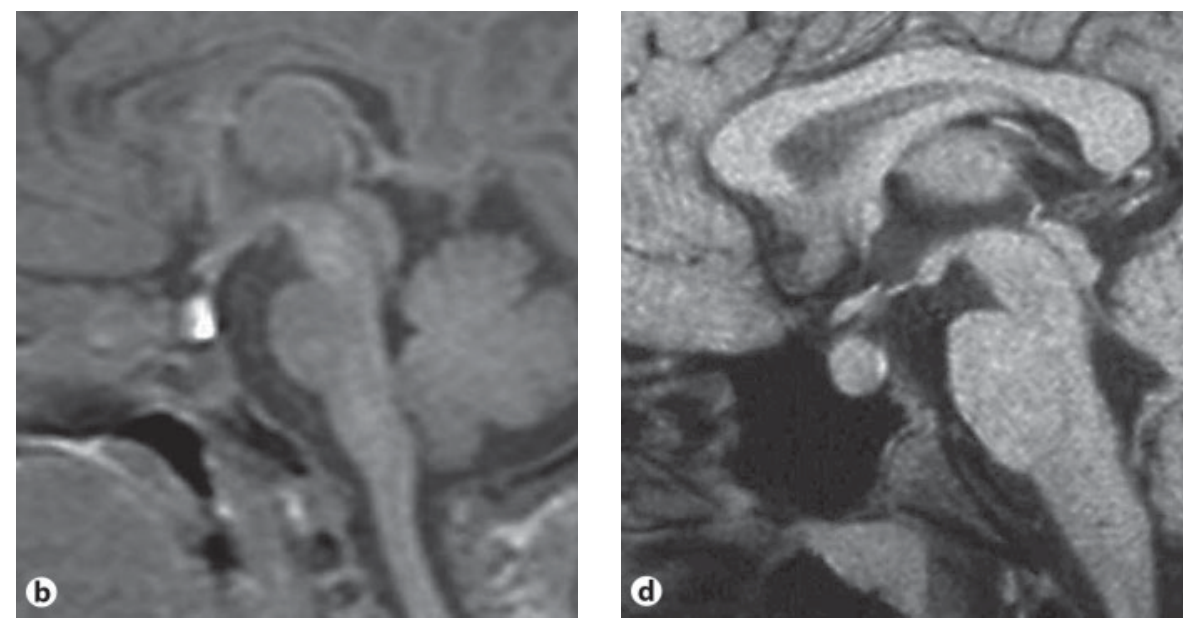

ties. T2-weighted axial slices may be useful. The olfactory bulbs and sulci are studied on T2-weighted coronal slices in cases of isolated gonadotropin deficiency.

\section{Normal Appearance of the Hypothalamo-Pituitary Axis in Children}

The pituitary gland originates from two structures in the embryo: the adenohypophysis develops from the ectodermal stomodeum, whereas an evagination of the diencephalon gives rise to the neurohypophysis. The fetal pituitary gland consists of the pars distalis (anterior lobe), the pars nervosa (posterior lobe) and the pars intermedia.
The pars intermedia undergoes involution during the third trimester of pregnancy. The residual lumen between the pars distalis and the pars intermedia decreases in size, forming Rathke's cleft, a narrow, non-visible cleft between the anterior and posterior lobes $[1,2]$.

In fetuses and infants under the age of 2 months, the entire pituitary gland is bright on $\mathrm{T} 1$ sequences, resulting in very similar signals for the adenohypophysis and the neurohypophysis. The brightness of the adenohypophysis may be accounted for by intense cellular activity in the pituitary gland during this period of development. High levels of protein synthesis may account for the short T1 values of the pituitary gland [3]. Moreover, the pituitary gland is bulbous in shape in this period, probably due to 
cellular hypertrophy [4]. Its upper margin later becomes flatter. At puberty, physiological pituitary hypertrophy is observed, with significant changes in the size and shape of this gland (convex upper margins) in girls, and changes in its size alone in boys [5] (fig. 1). After puberty, the pituitary gland decreases in size.

The T1 hypersignal of the neurohypophysis (visible at the posterior part of the sella turcica and observed in children and adults) has been attributed to storage of the neurophysin vasopressin complex [6]. A lack of T1 hypersignal has been reported in $10 \%$ of healthy subjects [7], but this percentage is clearly an overestimate, resulting from the technical conditions of MRI 20 years ago.

The signal of the normal pituitary gland and stalk is markedly enhanced by the intravenous injection of contrast medium. The anterior and posterior lobes differ in their vascularization: the superior hypophyseal arteries supply the median eminence. The neurohypophysis and stalk are supplied by the inferior hypophyseal arteries. The hypophyseal portal vessels supply the anterior lobe [1]. The timing of enhancement has been studied by Maghnie et al. [8].

Data are available concerning the height [9] or volume [10] of the normal pituitary gland as a function of age. The pituitary gland gradually increases in size until puberty. A pituitary gland less than $3 \mathrm{~mm}$ high is considered small. At puberty, the pituitary gland displays physiological hypertrophy and may be $8 \mathrm{~mm}$ high in boys and $10 \mathrm{~mm}$ high in girls [11]. No data are available concerning the normal dimensions of the pituitary stalk in children, but it is widely accepted that the maximum transverse diameter does not exceed $2 \mathrm{~mm}$ in children.

\section{Non-Tumoral Hypopituitarism}

Non-tumoral hypopituitarism includes the following.

Anterior pituitary deficiency: GH deficiency may be isolated (IGHD) or associated with other anterior pituitary hormone deficiencies which, in some cases, maybe related to a known genetic abnormality or associated with other malformations. Other isolated pituitary hormone deficiencies may be observed, the most common of which is isolated hypogonadotropic hypogonadism.

Posterior pituitary deficiency: CDI may be observed in the absence of tumor development.

\section{Anterior Pituitary Deficiency}

Detailed MRI analysis of the hypothalamo-pituitary axis is required for the detection of possible morphological abnormalities.

The adenohypophysis may appear normal (with reference to published data), hypoplastic (with a small height and usually with a concave upper border) or, very rarely, enlarged (an upper threshold of $5 \mathrm{~mm}$ can be used as the threshold for height during the prepubertal period). The height of the adenohypophysis should always be analyzed as a function of the child's pubertal status.

The bright neurohypophysis signal may be normally located or ectopic, in the pituitary stalk or at the level of the median eminence. Its position in the stalk should be noted.

The pituitary stalk can be normal, thin or not visible.

Detailed phenotypic description of this type is absolutely essential. Indeed, the type of hormone deficiency and the prognosis seem to differ as a function of the appearance of the hypothalamo-pituitary axis.

Pituitary height is thought to be directly related to $\mathrm{GH}$ levels, as GH-secreting cells are the most abundant cell population in the pituitary gland [12]. However, no correlation has been found between the size of the pituitary gland and the severity of the endocrine defect [13]. A hypoplastic adenohypophysis is a nonspecific sign observed in both groups of children, in those with IGHD and in those with multiple pituitary hormone deficiencies (MPHD). However, the prevalence of a normal adenohypophysis in patients with IGHD is twice that in those with MPHD [14]. In children with IGHD and hypoplastic adenohypophysis, the pituitary gland may spontaneously increase significantly in height after completion of spontaneous pubertal development $[15,16]$. An enlarged anterior pituitary gland has also been reported in some patients with rare molecular defects involving mutations in the Prop 1 and LHX 3 genes [17-19].

The ectopic posterior lobe (EPL) is always located at the median eminence if the stalk is not visible, but may be found anywhere along the stalk if the stalk is hypoplastic (fig. 2). The implications of EPL location are still unknown. However, it has been reported that patients in whom the pituitary stalk is visible and the EPL is found along the stalk may display increased GH secretion abilities in adulthood (after completion of GH therapy), whereas patients in whom the EPL is found at the median eminence continue to present severe GH deficiency [20]. Anterior pituitary hypoplasia is commonly reported in patients with an EPL and its prevalence is higher for a 

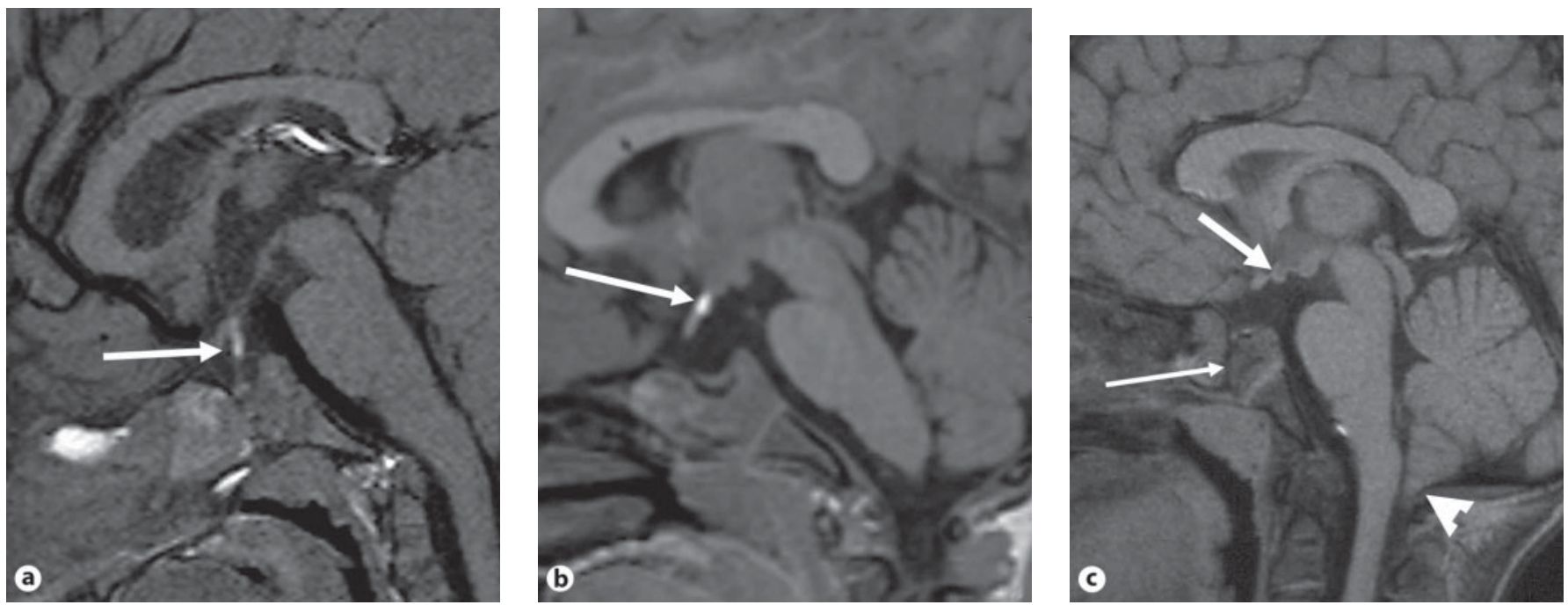

Fig. 2. T1-weighted midline sagittal slices showing hypoplastic adenohypophysis and ectopic posterior lobe. a An 18-month-old boy with GH deficiency and short stature $(-3 \mathrm{SD})$. The neurohypophysis is ectopic (arrow) on the proximal part of the stalk. The stalk is visible and appears very thin. b A 4-year-old girl with multiple pituitary hormone deficiencies. The neurohypophysis is ec- topic at the median eminence (arrow) and the stalk is not visible, even after contrast injection. c A 2-year-old boy with multiple pituitary hormone deficiencies. The neurohypophysis is ectopic at the median eminence (arrow) and the stalk is not visible. Note the persistent craniopharyngeal canal (thin arrow) and the Chiari I malformation (arrowhead).

MRI with gadolinium injection is more sensitive for the demonstration of the pituitary stalk in cases in which this structure is not visible on unenhanced images [25]. The presence of an ectopic posterior lobe is highly specific and predictive of GHD [12].

Associated cerebral abnormalities must be carefully sought because pituitary hormone deficits may also be present as part of a syndrome $[28,29]$. In our series of 60 patients with GH deficiency and EPL, 31 (52\%) presented associated malformative abnormalities. The most common malformations were cerebral, craniofacial and ocular, but cardiac, renal, intestinal, limb and skin abnormalities were also observed. Some of the children presented syndromes such as Currarino syndrome, Pallister-Hall syndrome (fig. 3) and Fanconi anemia [28]. Midline CNS malformations are observed with a high frequency and include optic nerve hypoplasia, Chiari I malformations (fig. 2c) and medial deviation of the carotid arteries [30]. MRI can also reveal callosal, septal or vermian agenesis, aqueductal stenosis, persistent craniopharyngeal canal, solitary median maxillary central incisor. This last malformation is difficult to diagnose clinically in newborns and may be associated with nasal pyriform aperture stenosis readily visible on computed tomography. Conversely, the discovery of such a developmental defect in a newborn should lead to cerebral MRI, 
Fig. 3. A 5-year-old boy with Pallister-Hall syndrome. T1-weighted midline sagittal slice (a) and T2-weighted coronal (b) slice. The adenohypophysis is small (large arrow), and the neurohypophysis is ectopic (thin arrow) at the median eminence. The hypothalamic hamartoma is visible (arrowhead) behind the neurohypophysis on the floor of the third ventricle and its intensity is similar to that of the cerebral parenchyma on $\mathrm{T} 1$ and $\mathrm{T} 2$ sequences. No contrast enhancement was observed within the hamartoma.
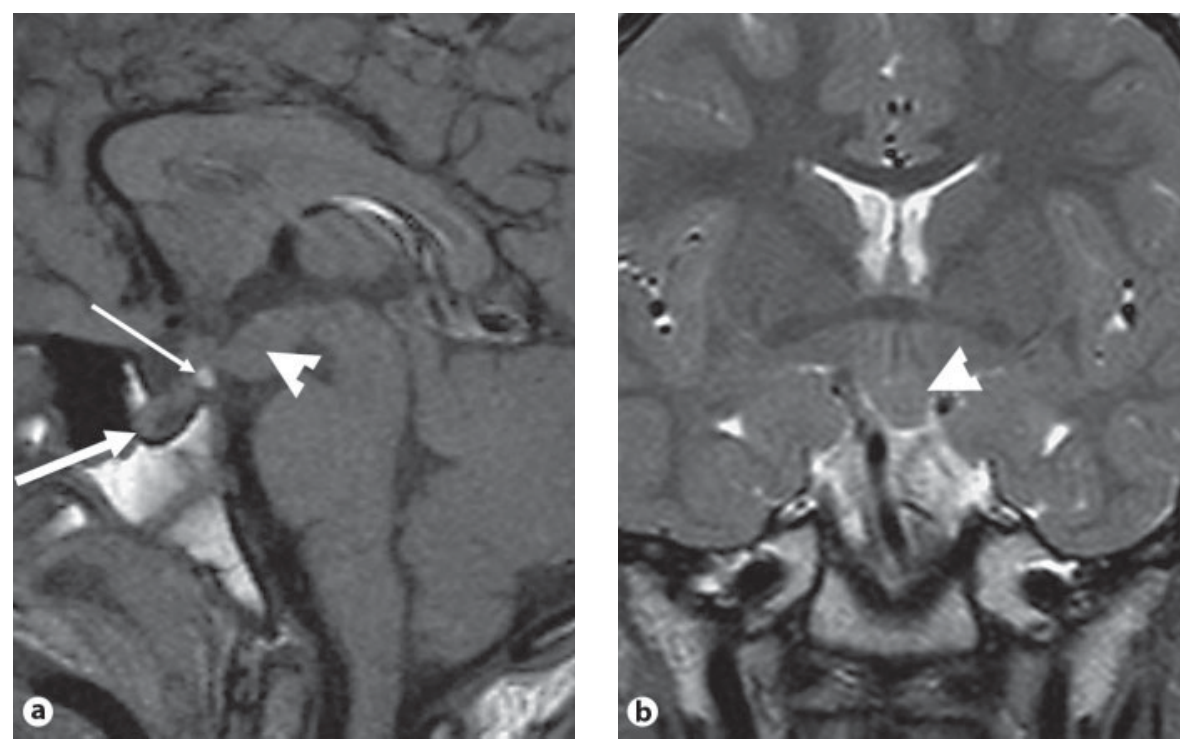

Table 1. Anterior pituitary deficiency: MRI findings and the genes implicated in humans

\begin{tabular}{lll}
\hline Pituitary deficiency & MRI & Genes $^{1}$ \\
\hline GH & Normal & GH-N \\
GH, partial Prl & Normal or hypoplastic AH & GHRH-R \\
GH, Prl, \pm TSH & Normal or hypoplastic AH & PIT-1 \\
GH, Prl, TSH, LH, FSH, \pm ACTH & Normal or hypoplastic or hyperplastic AH & PROP-1 \\
GH, Prl, TSH, LH, FSH, ACTH & Hypoplastic/normal AH, EPL & HESX1 $^{3}$ \\
GH, Prl, TSH, LH, FSH & Hypoplastic/hyperplastic AH & LHX3 $^{4}$ \\
GH, Prl, TSH, LH, FSH, ACTH & EPL & LHX4 $^{5}$ \\
GH, Prl, TSH, LH, FSH, ACTH & EPL & Sox $3^{6}$ \\
\hline
\end{tabular}

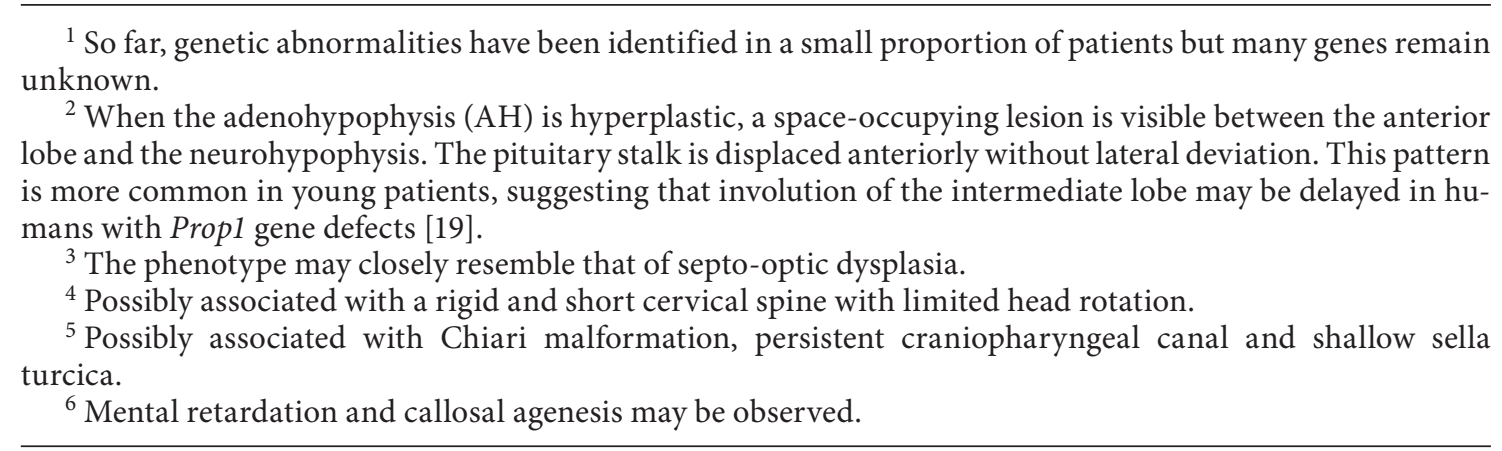

to search for abnormalities of the hypothalamo-hypopituitary axis [31, 32]. These findings account for a wide genetic heterogeneity in ectopic posterior lobe syndrome. Familial cases of GH deficiency with an ectopic posterior lobe have been reported with various transmission patterns: autosomal recessive or dominant, X-linked forms.
Such cases account for about $12 \%$ of all cases of GH deficiency. Considerable phenotypic variability may be observed within a given family $[1,28,33]$.

Positive cerebral MRI findings have prognostic value in patients with GH deficiency. Children with GH deficiency and CNS midline abnormalities (associated with 
Fig. 4. Kallmann syndrome in a 16-yearold boy with anosmia, pubertal retardation, ear abnormalities and syndactylia. T2-weighted coronal slice (a). The olfactory bulbs are not visible. Control (b) with highly visible olfactory bulbs (arrowheads). The morphology of the hypothalamo-pituitary axis is normal.
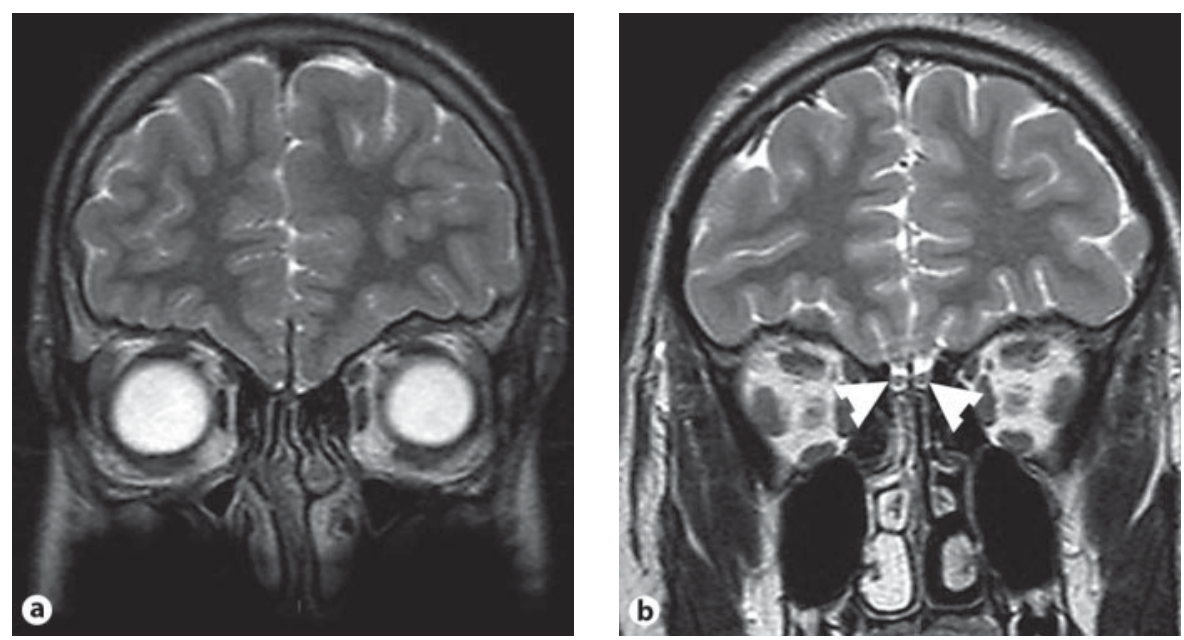

EPL or pituitary hypoplasia) have been shown to have significantly greater height gain after GH treatment than children with normal or hypoplastic pituitary gland (or with isolated CNS midline malformation), which is probably related to a more severe form of GH deficiency [34]. These findings highlight the great phenotypic variability of GH deficiency, as also demonstrated by the different patterns of growth response to $\mathrm{GH}$ replacement treatment during childhood.

Genetic defects of the GH axis have been identified and correlations between phenotype and genotype have been established [1, 19, 35-37] (table 1). However, these identified genetic defects account for very few cases of childhood hypopituitarism, notably forms associated with EPL.

\section{Hypogonadotropic Hypogonadism}

Hypogonadotropic hypogonadism and congenital olfactory deficit are common findings in Kallmann's syndrome, which may display X-linked or autosomal inheritance. Other abnormalities, such as cleft lip or palate, dental agenesis, renal abnormalities, hearing loss and cerebellar dysfunction may be associated. The morphology of the hypothalamo-pituitary axis appears normal on MRI scans. Some cases of pituitary hypoplasia have been reported. In case of olfactory deficit, the olfactory bulbs are absent or hypoplastic. The olfactory sulci may be normal, absent or hypoplastic. In no instance is an olfactory sulcus absent when a bulb is present $[21,38,39]$ (fig. 4).

MRI and Hypopituitarism

\section{Posterior Pituitary Deficiency}

CDI is rare in children. MRI can be very useful in searches for the cause of this condition [40]. In a series of 79 children with CDI, $52 \%$ were idiopathic. Where causes were identified, they included: Langerhans' cell histiocytosis (LCH) in 15\%; intracranial tumors (germinoma, craniopharyngioma, post-resection) in $23 \%$; familial DI in 6\%; post-traumatic CDI in 3\%, and autoimmune polyendocrinopathy in $1 \%$ of cases [41].

The loss of the posterior pituitary bright spot is a sensitive marker for CDI [42]. However, there are two exceptions, in which the posterior lobe remains visible: familial CDI, when evaluated during infancy or early childhood, and chronic neurogenic hypernatremia.

Familial CDI is caused by mutations of the gene encoding a preprohormone and involves the progressive postnatal degeneration of arginine vasopressin (AVP)producing neurons. The abnormal preprohormone could not be processed correctly and would eventually destroy the AVP-producing neurons. The accumulation of this preprohormone might account for the persistent posterior pituitary bright spot and for the variable appearance of MRI scans of members of the same family [40,43,44]. It has been suggested that these patients are able to store small amounts of AVP, but cannot release it normally [45].

Chronic neurogenic hypernatremia is observed in children presenting midline abnormalities of the brain, such as holoprosencephaly, callosal agenesis or septal agenesis. The underlying mechanism remains unclear, but there appears to be a defect in hypothalamic function,

Horm Res 2007;67:194-202 


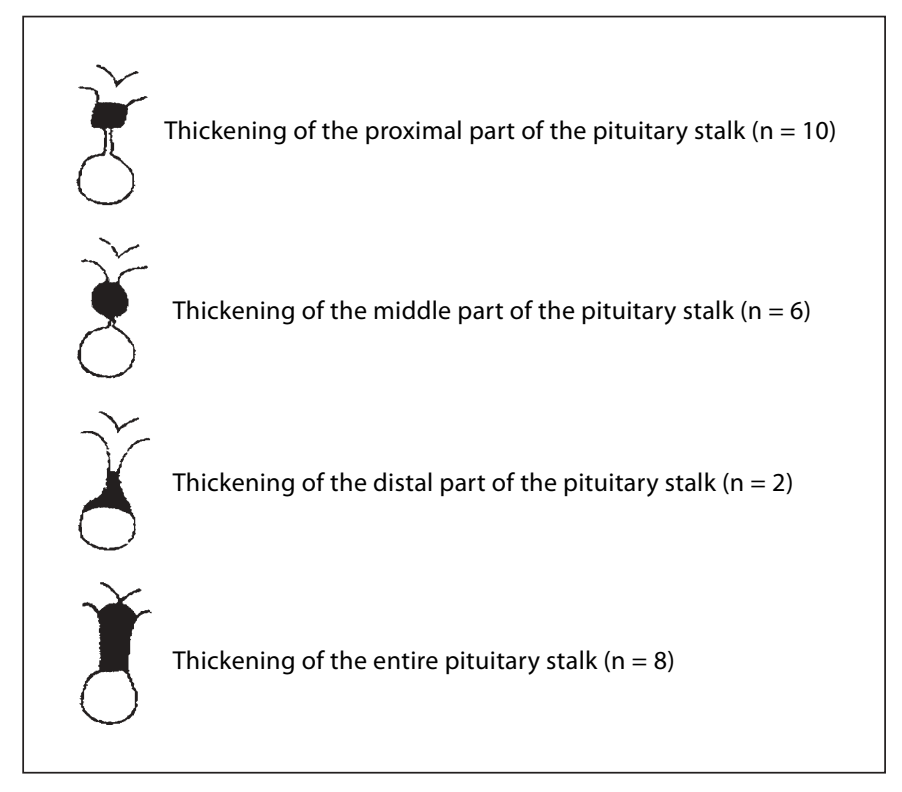

Fig. 5. Central diabetes insipidus and pituitary stalk thickening according to Léger et al. [48].

leading to the failure of the osmoreceptors, whereas the synthesis and storage of AVP remain intact $[46,47]$.

The size of the adenohypophysis is variable in patients with CDI. An increase in intrasellar content is suggestive of germinoma, which is associated with pituitary stalk thickening (PST). Hypoplasia of the adenohypophysis is observed in almost half of all cases and is often associated with thickened pituitary stalk. Anterior pituitary hormone deficiency, concerning GH deficiency and thyrotropin in particular, is observed in half of all patients with idiopathic CDI. Panhypopituitarism is less common. A gradual decrease in the size of the adenohypophysis is associated with an increase in the risk of an additional endocrine defect, i.e. GH deficiency [ 41 , 48].

The pituitary stalk is considered enlarged if at least part of the stalk is found to have a diameter of $>2.0 \mathrm{~mm}$ [48]. PST is observed in almost one third of children with CDI [49]. CDI with PST may be related to germinomas $(15 \%)$ or LCH (15\%) or may remain idiopathic (70\%) [41, 48]. MRI should always be performed after gadolinium injection in patients with CDI, to make it possible to check for abnormal enhancement within the stalk. PST may be the first sign of a germinoma or of stalk infiltration, as in LCH.

CDI with PST remains idiopathic in most cases. PST may be observed anywhere along the stalk, or may in-
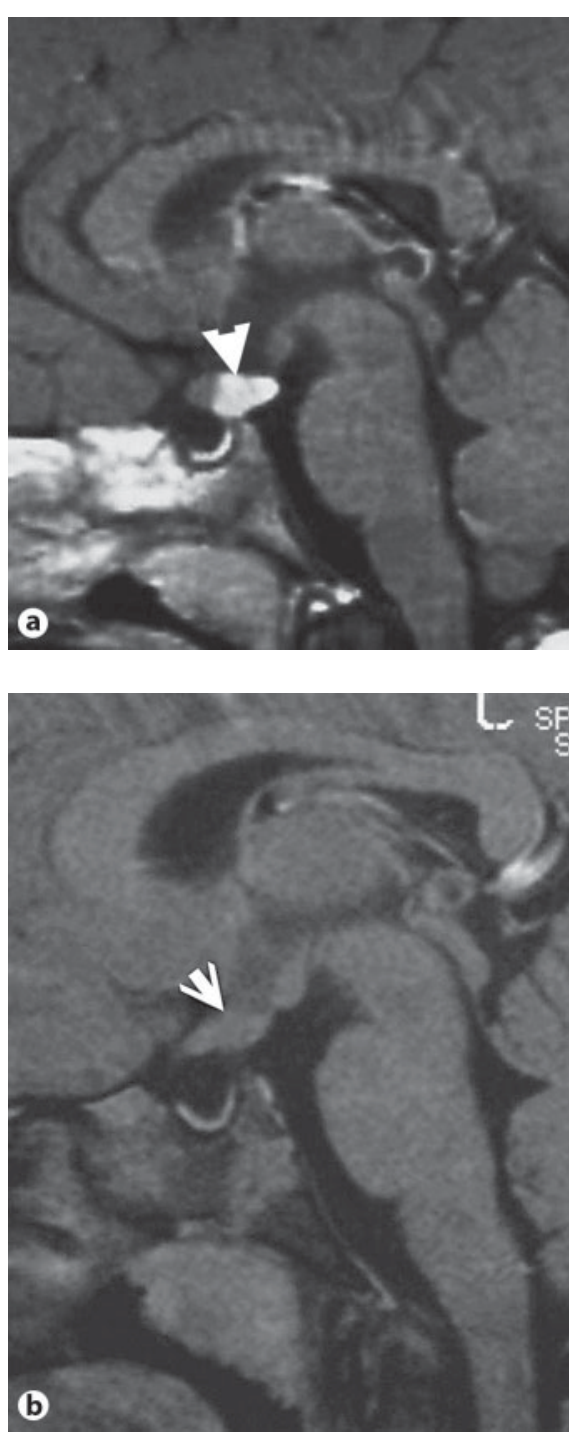

Fig. 6. Central diabetes insipidus and idiopathic pituitary stalk thickening. T1-weighted midline sagittal slices after contrast injection at 4.5 years (a) and 7.5 years (b). The adenohypophysis is hypoplastic, no hypersignal for the neurohypophysis is visible and there is a marked thickening of the pituitary stalk at the median eminence (arrowhead), enhanced at 4.5 years and decreased in size at 7.5 years. The enhancement of stalk thickening is no longer observed in children at this age.

volve the entire stalk (fig. 5). Biopsies in some adult patients demonstrate lymphocytic inflammation. Some patients have circulating antibodies against AVP neurosecretory cells, suggesting a possible autoimmune process. Spontaneous regression of PST has been observed in some children. Conversely, some patients show a progressive increase in PST, with the adenohypophysis remain- 
ing hypoplastic. Changes in the size of PST and in the size of the adenohypophysis (possibly associated with changes in PST enhancement) are observed during the first 2 or 3 years, with the appearance of the hypothalamo-pituitary axis remaining unchanged thereafter. The natural history of idiopathic CDI with PST is unpredictable (fig. 6). MRI and determinations of the tumor marker human chorionic gonadotropin (HCG) in serum and cerebrospinal fluid should be performed at diagnosis. MRI and determination of the tumor marker HCG in serum will be repeated every $3-6$ months during the first 3 years after the onset of CDI (frequency depending on whether the pituitary stalk progressively increases in size). Determination of the tumor marker HCG in cerebrospinal fluid will be performed during the follow-up only in the cases with an increasing size of the lesion. Malignant processes are unlikely to occur after 3 years. Careful MRI evaluation should then be performed once per year for 2 years and every 2-5 years thereafter, depending on the size and progression of the lesion. Biopsy is not recommended in cases of PST in which the lesion is $<7 \mathrm{~mm}$ in diameter and is well delimited $[48,50]$.
Other exceptional causes of PST in children include tuberculosis and sarcoidosis [51, 52].

\section{Conclusion}

MRI is essential for the evaluation of the hypothalamo-pituitary axis in children, and a detailed description of hypothalamo-pituitary axis abnormalities should be produced. This description has diagnostic (visibility of EPL, absence of olfactory bulbs in Kallmann's syndrome, absence of visibility of the neurohypophysis in CDI) and prognostic (some prognostic data are correlated with the phenotype) implications. MRI findings also extend the phenotypic profile associated with non-tumoral GH deficiency and should help to increase our understanding of genotype-phenotype relationships in these patients. However, the etiology remains unknown in many cases. Careful phenotypic description of these patients may facilitate the identification of cases of anterior pituitary deficiency requiring further investigation in collaboration with molecular biologists.

\section{References}

1 Rosenbloom AL, Connor EL: Hypopituitarism and other disorders of the growth hormone and insulin-like growth factor axis; in Lifshitz F (ed): Pediatric Endocrinology, ed 4. New York, Dekker, 2003, pp 47-86.

$\checkmark 2$ Kollias SS, Ball WS, Prenger EC: Review of the embryologic development of the pituitary gland and report of a case of hypophyseal duplication detected by MRI. Neuroradiology 1995;37:3-12.

$\checkmark 3$ Wolpert SM, Osborne M, Anderson M, Runge VM: The bright pituitary gland. A normal MR appearance in infancy. AJNR Am J Neuroradiol 1988;9:1-3.

4 Tien RD, Kucharczyk J, Bessette J, Middleton M: MR imaging of the pituitary gland in infants and children: changes in size, and MR signal with growth and development. AJR Am J Roentgenol 1992;158:1151-1154.

5 Elster AD, Chen MYM, Williams DW, Key LL: Pituitary gland: MR imaging of physiologic hypertrophy in adolescence. Radiology 1990; 174:681-685.

-6 Kurokawa H, Fujisawa I, Nakano Y, Kimura H, Akagi K, Ikeda, K, Uokawa K, Tanaka Y: Posterior lobe of the pituitary gland: correlation between signal intensity on T1-weighted MR images and vasopressin concentration. Radiology 1998;207:79-83.

7 Colombo N, Berry I, Kucharczyk J, Kucharczyk W, de Groot J, Larson T, Norman D, Newton TH: Posterior pituitary gland: ap- pearance on MR images in normal and pathologic states. Radiology 1987;165:481485.

-8 Maghnie M, Genovese E, Arico M, Villa A, Beluffi G, Campani R, Severi F: Evolving pituitary hormone deficiency is associated with pituitary vasculopathy: dynamic MR study in children with hypopituitarism, diabetes insipidus, and Langerhans cell histiocytosis. Radiology 1994;193:493-499.

$\checkmark 9$ Argyropoulou M, Perignon F, Brunelle F, Brauner R, Rappaport R: Height of normal pituitary gland as a function of age evaluated by magnetic resonance imaging in children. Pediatr Radiol 1991;21:247-249.

10 Fink AM, Vidmar S, Kumbla S, Pedreira C, Kanumakala S, Williams C, Carlin JB, Cameron FJ: Age-related pituitary volumes in prepubertal children with normal endocrine function: volumetric magnetic resonance data. J Clin Endocrinol Metab 2005;90: 3274-3278.

11 Maghnie M, Ghirardello S, Genovese E: Magnetic resonance imaging of the hypothalamus-pituitary unit in children suspected of hypopituitarism: who, how and when to investigate. J Endocrinol Invest 2004;27: 496-509.

12 Tillmann V, Tang VWM, Hughes DG, Wright NB, Clayton PE: Magnetic resonance imaging of the hypothalamic-pituitary axis in the diagnosis of growth hormone defi- ciency. J Pediatr Endocrinol Metab 2000;13: 1577-1583.

13 Bozzola M, Mengarda F, Sartirana P, Tato L, Chaussain JL: Long-term follow-up evaluation of magnetic resonance imaging in the prognosis of permanent GH deficiency. Eur J Endocrinol 2000;143:493-496.

14 Kornreich L, Horev G, Lazar L, Schwarz M, Sulkes J, Pertzelan A: MR findings in growth hormone deficiency: correlation with severity of hypopituitarism. AJNR Am J Neuroradiol 1998;19:1495-1499.

15 Bozzola M, Adamsbaum C, Biscaldi I, Zecca M, Cisternino M, Genovese E, Richard I, Kalifa G, Chaussain JL: Role of magnetic resonance imaging in the diagnosis and prognosis of growth hormone deficiency. Clin Endocrinol 1996;45:21-26.

16 Maghnie M, Strigazzi C, Tinelli C, Autelli M, Cisternino M, Loche S, Severi F: Growth hormone $(\mathrm{GH})$ deficiency (GHD) of childhood onset: reassessment of GH status and evaluation of the predictive criteria for permanent GHD in young adults. J Clin Endocrinol Metab 1999;84:1324-1328.

$\checkmark 17$ Bhangoo AP, Hunter CS, Savage JJ, Anhalt H, Pavlakis S, Walvoord EC, Ten S, Rhodes SJ: A Novel LHX3 mutation presenting as combined pituitary hormonal deficiency. J Clin Endocrinol Metab 2006;91:747-753. 
-18 Netchine I, Sobrier ML, Krude H, Schnabel D, Maghnie M, Marcos E, Duriez B, Cacheux V, Moers A, Goossens M, Gruters A, Amsellem S: Mutations in LHX3 result in a new syndrome revealed by combined pituitary hormone deficiency. Nat Genet 2000;25: $182-186$.

19 Voutetakis A, Argyroupoulou M, Sertedaki A, Livadas S, Xekouki P, Maniati-Christidi M, Bossis I, Thalassinos N, Patronas N, Dacou-Voutetakis C: Pituitary magnetic resonance imaging in 15 patients with Prop1 gene mutations: pituitary enlargement may originate from the intermediate lobe. J Clin Endocrinol Metab 2004;89:2200-2206.

$\checkmark 20$ Léger J, Danner S, Simon D, Garel C, Czernichow P: Do all patients with childhoodonset growth hormone deficiency (GHD) and ectopic neurohypophysis have persistent GHD in adulthood? J Clin Endocrinol Metab 2005;90: 650-656.

-21 Argyropoulou M, Kiortsis DN: MRI of the hypothalamic-pituitary axis in children. Pediatr Radiol 2005;35:1045-1055.

>22 Chen S, Léger J, Garel C, Hassan M, Czernichow P: Growth hormone deficiency with ectopic neurohypophysis: anatomical variations and relationship between the visibility of the pituitary stalk asserted by magnetic resonance imaging and anterior pituitary function. J Clin Endocrinol Metab 1999;84: 2408-2413.

$\checkmark 23$ Ultmann MC, Siegel SF, Hirsch WL, Finegold DN, Foley TP: Pituitary stalk and ectopic hyperintense T1 signal on magnetic resonance imaging. Am J Dis Child 1993;147: 647-652.

24 Maghnie M, Genovese E, Villat A, Spagnolo L, Campan R, Severi F: Dynamic MRI in the congenital agenesis of the neural pituitary stalk syndrome: the role of the vascular pituitary stalk in predicting residual anterior pituitary function. Clin Endocrinol 1996;45: 281-290.

-25 Genovese E, Maghnie M, Beluffi G, Villa A, Sammarchi L, Severi F, Campani R: Hypothalamic-pituitary vascularization in pituitary stalk transection syndrome: is the pituitary stalk really transected? The role of gadolinium-DTPA with spin-echo T1 imaging and turbo-FLASH technique. Pediatr Radiol 1997;27:48-53.

-26 Fujisawa I, Kikuchi K, Nishimura K, Togashi K, Itoh K, Noma S, Minami S, Sagoh T, Hiraoka T, Momoi T, Mikawa $\mathrm{H}$, Nakano $\mathrm{Y}$, Itoh H, Konishi J: Transection of the pituitary stalk: development of an ectopic posterior lobe assessed with MR imaging. Radiology 1987;165:487-489.

-27 Kelly WM, Kucharczyk W, Kucharczyk J, Kjos B, Peck WW, Norman D, Newton TH: Posterior pituitary ectopia: an MR feature of pituitary dwarfism. AJNR Am J Neuroradiol $1988 ; 9: 453-460$
28 Simon D, Hadjiathanasiou C, Garel C, Czernichow $\mathrm{P}$, Léger J: Phenotypic variability in children with growth hormone deficiency associated with posterior pituitary ectopia. Clin Endocrinol (Oxf) 2006;64:416-422.

29 Arifa N, Léger J, Garel C, Czernichow P, Hassan M: Cerebral anomalies associated with growth hormone insufficiency in children: major markers for diagnosis Arch Pediatr 1999;6: 14-21.

30 Hamilton J, Blaser S, Daneman D: MR Imaging in idiopathic growth hormone deficiency. AJNR Am J Neuroradiol 1998;19:16091615.

31 Beregszaszi M, Léger J, Garel C, Simon D, François M, Hassan M, Czernichow P: Nasal pyriform aperture stenosis and absence of the anterior pituitary gland: report of two cases. J Pediatr 1996;128:858-861.

32 Guilmin-Crépon S, Garel C, Baumann C, Brémond-Gignac D, Bailleul-Forestier I, Magnier S, Castanet C, Czernichow P, Van den Abbeele T, Léger J: High proportion of pituitary abnormalities and other congenital defects in children with congenital nasal pyriform aperture stenosis. Pediatr Res 2006;60:478-484.

33 Hamilton J, Chitayat D, Blaser S, Cohen LE, Phillips JA, Daneman A: Familial growth hormone deficiency associated with MRI abnormalities. Am J Med Genet 1998;80:128132.

34 Zenaty D, Garel C, Limoni C, Czernichow P, Léger J: Presence of magnetic resonance imaging abnormalities of the hypothalamic-pituitary axis is a significant determinant of the first 3 years growth response to human growth hormone treatment in prepubertal children with nonacquired growth hormone deficiency. Clin Endocrinol 2003;58:647652.

35 Osorio MG, Marui S, Jorge AA, Latronico AC, Lo LS, Leite CC, Estefan V, Mendoca BB, Arnhold IJ: Pituitary magnetic resonance imaging and function in patients with growth hormone deficiency with and without mutations in GHRH-R, GH-1, or PROP-1 genes. J Clin Endocrinol Metab 2002;87: 5076-5084.

36 Maghnie M, Loche S, Cappa M: Pituitary magnetic resonance imaging in idiopathic and genetic growth hormone deficiency. J Clin Endocrinol Metab 2003;88:1911-1912.

37 Dattani MT: Growth hormone deficiency and combined pituitary hormone deficiency: does the genotype matter? Clin Endocrinol 2005;63:121-130.

38 Yousem DM, Geckle RG, Bilker W, Mc Keown DA, Doty RL: MR evaluation of patients with congenital hyposmia or anosmia. AJR Am J Roentgenol 1996;166:439-443.

39 Truwit CL, Barkovich AJ, Grumbach MM, Martini JJ: MR imaging of Kallmann syndrome, a genetic disorder of neuronal migration affecting the olfactory and genital systems. AJNR Am J Neuroradiol 1993;14 827-838.
40 Czernichow P: Central diabetes insipidus; in Rappaport R, Amselem S (eds): Hypothalamic-Pituitary Development. Genetic and Clinical Aspects. Endocr Dev. Basel, Karger, 2001, vol 4, pp 162-174.

41 Maghnie M, Cosi G, Genovese E, Manca-Bitti ML, Cohen A, Zecca S, Tinelli C, Gallucci M, Bernasconi S, Boscherini B, Severi F, Arico M: Central diabetes insipidus in children and young adults. N Engl J Med 2000;343: 998-1007.

42 Tien R, Kucharczyk J, Kucharczyk W: MR imaging of the brain in patients with diabetes insipidus. AJNR Am J Neuroradiol 1991; 12:533-542.

43 Miyamoto S, Sasaki N, Tanabe Y: Magnetic resonance imaging in familial central diabetes insipidus. Neuroradiology 1991;33:272273.

44 Maghnie M, Villa A, Arico M, Larizza D, Pezzotta S, Beluffi G, Genovese E, Severi F: Correlation between magnetic resonance imaging of posterior pituitary and neurohypophyseal function in children with diabetes insipidus. J Clin Endocrinol Metab 1992;74: 795-800.

45 Ozata M, Tayfun C, Kurtaran K, Yetkin I, Beyhan Z, Corakci, Caglayan S, Alemdaroglu A, Gündogan MA: Magnetic resonance imaging of posterior pituitary for evaluation of the neurohypophyseal function in idiopathic and autosomal dominant neurohypophyseal diabetes insipidus. Eur Radiol 1997;7:1098-1102.

46 Garel C, Léger J, Legrand I, Stempfle N, Maiza D, Czernichow P, Hassan M: Aspect IRM des hypernatrémies neurogènes. Rev Im Med 1995;7:29-32.

47 Abernethy LJ, Qunibi MA, Smith CS: Normal MR appearances of the posterior pituitary in central diabetes insipidus associated with septo-optic dysplasia. Pediatr Radiol 1997;27:45-47.

48 Léger J, Velasquez A, Garel C, Hassan M, Czernichow P: Thickened pituitary stalk on magnetic resonance imaging in children with central diabetes insipidus. J Clin Endocrinol Metab 1999;84:1954-1960.

49 Alter CA, Bilaniuk LT: Utility of magnetic resonance imaging in the evaluation of the child with central diabetes insipidus. J Pediatr Endocrinol Metab 2002;15:681-687.

50 Czernichow P, Garel C, Léger J: Thickened pituitary stalk on magnetic resonance imaging in children with central diabetes insipidus. Horm Res 2000;53(suppl 3): 61-64.

-51 Tien RD, Newton TH, McDermott MW, Dillon WP, Kucharczyk J: Thickened pituitary stalk on MR images in patients with diabetes insipidus and Langerhans cell histiocytosis. AJNR Am J Neuroradiol 1990;11:703-708.

52 Andronikou S, Furlan G, Fieggen AG, Wilmshurst J: Two unusual causes of pituitary stalk thickening in children without clinical features of diabetes insipidus. Pediatr Radiol 2003;33:499-502. 